- Highlights problems concerning the low level of restorative care provided for carious primary teeth in general practice.

- Presents audit data from a single GDP of a simplified method of placing preformed metal

- Although the technique looks promising, the need for prospective randomised clinical trials before the technique is adopted, is stressed.

\title{
A novel technique using preformed metal crowns for managing carious primary molars in general practice - A retrospective analysis
}

\author{
N. P. T. Innes, ${ }^{1}$ D. R. Stirrups, ${ }^{2}$ D. J. P. Evans, ${ }^{3}$ N. Hall ${ }^{4}$ and M. Leggate ${ }^{5}$
}

\begin{abstract}
Background There is a high level of untreated dental decay in primary teeth in Scotland. Despite evidence for the efficacy of preformed metal crowns (PMCs) for the restoration of primary molars, few are placed in general practice, possibly due to the interventive nature of the clinical procedure. There is, however, a novel way of placing PMCs involving no local anaesthesia, no caries removal and no preparation of the tooth: the Hall technique. Aim To investigate the survival of carious primary teeth treated with PMCs placed using a novel, simplified method - the Hall technique.

Setting General dental practice, in Scotland.

Methods A retrospective analysis of practice records from one general practitioner, from 1988 to 2001. The majority of the 978 PMCs fitted on 259 children, using the Hall technique, were placed when there was clinical evidence of approximal caries into dentine. The Kaplan-Meier approach was used to analyse survival times and the Mantel-Haenszel Log rank test for comparison between tooth types.

Results For all tooth types, the probability of surviving three years without being extracted or the PMC being lost, was 73.4\% (95\% confidence interval $70.1 \%$ to $76.4 \%$ ), and for five years was $67.6 \%$ (95\% confidence interval $63.3 \%$ to $71.5 \%$ ). The probability of surviving without extraction alone for three years was $86.0 \%$ (95\% confidence interval $83.2 \%$ to $88.4 \%$ ), and for five years was $80.5 \%$ (95\% confidence interval 76.5\% to 83.9\%).

Conclusion Hall technique restorations placed on primary molars with decay clinically into dentine, by a single operator in general dental practice, have a similar success rate to some other, more conventional, restorative techniques. The technique requires further evaluation through a prospective randomised control clinical trial before its use could be generally recommended.
\end{abstract}

\section{INTRODUCTION}

The management of carious primary molars in children is problematic. Evidence from clinical trials indicates that conventional

$1^{*}$ General Dental Practitioner/CSO Research Training Fellow, 18 Dundee Street, Carnoustie, Dundee DD7 7PD; 2 Professor of Orthodontics, Dundee Dental Hospital \& School, Park

Place, Dundee DD1 4HR; ${ }^{3}$ Senior Lecturer/Hon. Consultant in Paediatric Dentistry, Dundee Dental Hospital \& School, Park Place, Dundee DD1 4HR; ${ }^{4}$ General Dental Practitioner, The Dental Surgery, Lairg Health Centre, Lairg, Sutherland: ${ }^{5}$ General Dental

Practitioner/Honorary Research Fellow, 2 Westfield Road, Aberdeen, AB25 4NG

${ }^{*}$ Correspondence to: Nicola Innes

Email:n.p.innes@dundee.ac.uk

\section{Refereed paper}

Accepted 14 April 2005

doi: 10.1038/sj.bdj.4813466

(๑) British Dental Journal 2006; 200: 451-454 restorative techniques using amalgam, composite or compomer materials can be successful. ${ }^{1-10}$ However, the majority of these trials were carried out in either secondary care or specialist private practices. A recent evaluation of restorations placed by general dental practitioners in the UK found far less favourable results ${ }^{11}$ and, in fact, the justification and desirability of even attempting restorative management of carious primary teeth in general dental practice has been questioned. ${ }^{11,12}$

Currently accepted best practice for the management of carious primary molars involving two or more surfaces is the placement of a preformed metal crown (PMC) ${ }^{13,14}$ and there is evidence to support this approach. ${ }^{15}$ However, PMCs are little used in general practice, comprising only $0.4 \%$ of all restorations placed in children's teeth in Scotland in 2001. ${ }^{16}$ Additionally, primary teeth commonly remain unrestored, especially in the younger child; the care index (the proportion of carious teeth which have been restored) is currently only 9\% for 5-year-olds in Scotland. ${ }^{17}$ The high levels of dental disease in primary teeth, and its inadequate management, remains a major public health issue for children, and one with a significant impact on their lives; 15\% of Scottish children have already had at least one tooth extracted by the age of five years old, ${ }^{17}$ and this rises to $42 \%$ by the age of eight years. ${ }^{18}$ In addition, many children are having to accept toothache as a part of their childhood; with nearly half of all children with decayed primary teeth reported to have attended their general dental practitioner with dental pain. ${ }^{19}$ Set against this background, there would seem to be some scope for the investigation of alternative approaches to the management of carious primary teeth. If an alternative technique was found to be simpler and more acceptable to children, their parents and general dental practitioners than the conventional restorative approach, yet just as effective, then it might be more readily applied in the general practice setting.

While carrying out an audit of child dental care in general practice in the Grampian region of Scotland, it became apparent that a general dental practitioner (NH) had been placing PMCs for many years using a novel technique. Standard teaching ${ }^{14}$ for the placement of PMCs requires the use of local anaesthetic, complete caries removal and tooth reduction mesially, distally and occlusally. Following this, crowns are crimped, trimmed and polished as necessary before cementation. However, the dental practitioner had been placing the crowns without local anaesthetic, caries removal or any tooth preparation at all. An appropriately sized PMC would 


\begin{tabular}{|c|c|}
\hline \multicolumn{2}{|l|}{ Ascribed success } \\
\hline Crown present & $\begin{array}{l}\text { Date of the last examination before a child was lost to } \\
\text { follow up, or if the arbitrary study cut off date of } 1 \\
\text { January } 2001 \text { was reached with the crown still not } \\
\text { 'extracted', 'lost' or 'shed'. }\end{array}$ \\
\hline Tooth shed & $\begin{array}{l}\text { Tooth shed with no further intervention. As the date } \\
\text { at which primary teeth were shed was not recorded, } \\
\text { it was decided, in order to allow survival analysis, to } \\
\text { assume shedding of first primary molars at } 10.0 \\
\text { years of age, and second primary molars at } 11.0 \text { years } \\
\text { of age. }\end{array}$ \\
\hline \multicolumn{2}{|l|}{ Ascribed failure } \\
\hline Crown lost, tooth present & PMC became de-cemented. \\
\hline Tooth extracted & $\begin{array}{l}\text { Tooth required extraction. All symptomatic teeth were } \\
\text { extracted. Some teeth were extracted for } \\
\text { orthodontic reasons but as this was not recorded in } \\
\text { the records at the time, these were all treated as } \\
\text { failures. }\end{array}$ \\
\hline
\end{tabular}

\begin{tabular}{|c|c|c|}
\hline Ascribed success & $n$ & $\%$ \\
\hline Crown present & 406 & 42 \\
\hline Tooth shed & 336 & 34 \\
\hline \multicolumn{3}{|l|}{ Ascribed failure } \\
\hline Crown lost, tooth present & 124 & 13 \\
\hline Tooth extracted & 112 & 11 \\
\hline
\end{tabular}

\begin{tabular}{lcc} 
Table $\mathbf{3}$ Outcome measures for $\mathbf{1 1 4}$ preformed metal crowns which were re- \\
cemented following crown loss, until failure or censor date \\
\hline Ascribed success & $n$ & $\%$ \\
\hline Crown present & 53 & 46 \\
\hline Tooth shed & 29 & 25 \\
\hline Ascribed failure & & \\
\hline Crown lost, tooth present & 19 & 17 \\
\hline Tooth extracted & 13 & 11 \\
\hline
\end{tabular}

be selected and filled with glass ionomer cement before being seated over the carious primary molar using either finger pressure, or the child's own occlusal force. To avoid confusion, this technique will now be referred to as the Hall technique, and a typical case is shown in Figure 1. The dentist stated that in her experience, the Hall technique was acceptable to patients and parents, quick, and easy to use. It was also her impression that the technique was clinically effective in the management of carious primary molars, and she invited us to review her practice records to determine if this was the case.

\section{AIMS AND OBJECTIVES}

To investigate the survival of PMCs, placed by a single practitioner using the Hall technique, on carious primary molars.

\section{MATERIALS AND METHODS}

The practice records of a single dental practitioner $(\mathrm{NH})$ were scrutinised by a trained data abstractor for all records relating to the placement of PMCs on primary molars. All PMCs fitted to primary molars during the period of 1 March 1988 until the cut-off date of 1 January 2001 were included in the analysis. During this 13 year period, all PMCs were fitted using the Hall technique, and cemented with glass ionomer cement (AquaCem, Dentsply). Radiographs were not routinely taken and crowns were usually only placed once marginal ridge breakdown due to caries had occurred. Crowns were not placed on any teeth with clinical signs or symptoms of pulpal involvement. The practice patient base was a mixed urban and rural population, with a regional dmft of 1.9 in $1997 / 98 .{ }^{20}$
Most children had more than one tooth treated with the Hall technique. However, the data were analysed on the basis of each tooth rather than each child. Data collected included the tooth to which the crown was fitted, the date of fitting and the age of the child at the time. The outcome measure, and the date at which it applied, were also recorded. The outcome measures used are shown in Table 1.

The survival times were analysed using a Kaplan-Meier ${ }^{21}$ nonparametric test, commonly used in medical statistics with rightcensored data. This is when there is no possibility of following to failure which, in this study, was when the teeth exfoliated or children were lost to follow up before 'extracted' or 'crown lost' outcomes occurred. The date at which data were censored was taken to be the last time at which the tooth was seen. Comparisons between tooth types were carried out using the Mantel-Haenszel Log rank test. ${ }^{22}$ Data were entered into a Microsoft Excel spreadsheet and analysed using Unistat (Unistat Ltd, Unistat House, 4 Shirtland Mews, Maida Vale, London W9 3DY) software.

\section{RESULTS}

During the study period, 978 PMCs were fitted to 259 children. The mean age of the children when the PMCs were fitted was five years nine months, with the distribution shown in Figure 2. The mean number of PMCs fitted per child was four, and the distribution is shown in Figure 3. The numbers of PMCs allocated to each of the four outcome criteria are shown in Table 2.

The results of the survival analysis are shown in Figure 4. For all tooth types, the probability of the PMCs surviving for three years (tooth not extracted or crown de-cemented), was $73.4 \%$ (95\% confidence interval $70.1 \%$ to $76.4 \%$ ) and for five years, $67.6 \%$ (95\% confidence interval 63.3\% to 71.5\%). Analysis of the data indicated that there was no significant difference in PMC survival on first primary molars compared with second primary molars at three years or at five years.

The probability of a tooth surviving without being extracted (ie excluding crowns becoming de-cemented; 'lost') was 86.0\% at three years and $80.5 \%$ at five years.

Of the 124 PMCs which became de-cemented, 114 (92\%) were re-cemented and the outcome measures for these PMCs are shown in Table 3.

\section{DISCUSSION}

The reported success rate of conventional restorations in carious primary molars has ranged between 70\%-95\% after two years and 50\%-93\% after three years depending on the material used. ${ }^{1-10}$ The results of a recent systematic review ${ }^{23}$ on the longevity of dental restorations in the primary and permanent dentition are shown in Figure 5. When compared with these data, the reported survival rate of the Hall technique (73.4\% after three years and 67.6\% after five years) would seem better than those reported for glass ionomer materials and broadly equivalent to those reported for composite materials. However, caution has to be exercised when comparing data on longevity of restorations from different clinical trials. Settings for such trials can vary from specialist private practices to community clinics, with very few being run in general dental practice, where the majority of child dental care is provided in the UK. In addition, the outcome measures for ascribing restoration success or failure can vary between different studies. A randomised control clinical trial, of split mouth design would allow a valid comparison to be made of the survival rate of the Hall technique against conventional restorations, and this trial is currently underway.

The similarity between the survival rates for some conventional restorations and the Hall technique is of particular interest as there was no attempt at even partial caries removal when using the Hall technique, the caries simply being sealed in beneath the PMC. There 
is indirect evidence in support of this approach for primary molars from studies investigating the effectiveness of partial caries removal, followed by sealing the cavity with a restorative material, which report that caries progression was either arrested or at least significantly slowed down. ${ }^{24-27}$ Again, caution must be exercised when comparing retrospective clinical outcome audit data with data obtained from properly conducted, prospective clinical trials. Arguably, retrospective studies are one of the weaker types of research due to inherent problems with bias, calibration and other factors. Nevertheless, when analysing data in the current outcome audit, care was taken to ensure that whenever there was uncertainty in ascribing failure or censoring the data, the bias was against the intervention. For example, all extractions were recorded as crown failures, although some were for orthodontic reasons, or as part of multiple extractions under general anaesthesia. In addition, the censoring date was taken as the last date a patient was seen with the crown in place, rather than using the conventional practice of taking the middle of the interval between the crown last being recorded as present and a subsequent visit when it was noted to be absent.

Another factor which would tend to bias against the Hall technique is that the practitioner did not routinely use radiography to diagnose caries in children of this age. The PMCs were mainly only fitted to molars where the marginal ridge had fractured, a stage at which a majority of the teeth would have had histological evidence of pulpal involvement. ${ }^{28}$ In contrast, many of the studies looking at the longevity of conventional restorative techniques did use radiography, which is known to allow caries to be diagnosed at an earlier stage than by visual examination alone, ${ }^{29}$ and it might be assumed that the samples involved had a higher proportion of relatively early lesions compared with the Hall sample.

As the PMC is fitted with no tooth reduction, the occlusion would have been temporarily propped open. However, Dr Hall stated that the occlusion tended to equilibrate by the next recall appointment and none of her patients reported TMJ pain. Nevertheless, the effect of propping open the bite with a premature unilateral contact, which is inevitable with the Hall technique, will need further investigation through long term follow up with a prospective clinical trial, before any possible adverse consequences can be evaluated.

It could also be argued that the success rate of managing carious primary molars with the Hall technique is comparable with that obtained from a non-restorative approach as reported by Levine et al., ${ }^{12}$ and Tickle et al. ${ }^{11}$ However, in these studies, 'failure' was ascribed if the tooth required either extraction or a course of antibiotics; otherwise, the management was described as successful. These are relatively extreme criteria compared with those used in the current study, where failure was ascribed not only if the tooth required extraction, but also if the PMC simply became de-cemented, and crowns in this category formed 53\% of the 'failure' group. Of these PMCs, 92\% were re-cemented and only 11\% of this sample subsequently required extraction. It should also be noted, however, that the proportion of extractions to lost restorations in the 'failure' group for the Hall technique is considerably higher than for the clinical trials ${ }^{1-10}$ previously referred to, although incomplete reporting of study results makes it difficult to ascertain accurate figures for some of these trials. Clearly, high quality, prospective randomised clinical trials in primary care are required to investigate the relative merits of the non-restorative, prevention-only approach; the Hall technique, and conventional restorative care.

An apparent advantage of the Hall technique over conventional techniques for managing carious primary molars is that it involves no local anaesthetic injections, caries removal or tooth preparation of any kind. It does, however, require a child to tolerate biting a rigid metal crown into position, through potentially tight contact points, without any local anaesthesia. In this study, all the crowns were fitted by one experienced practitioner (NH). In order to assess
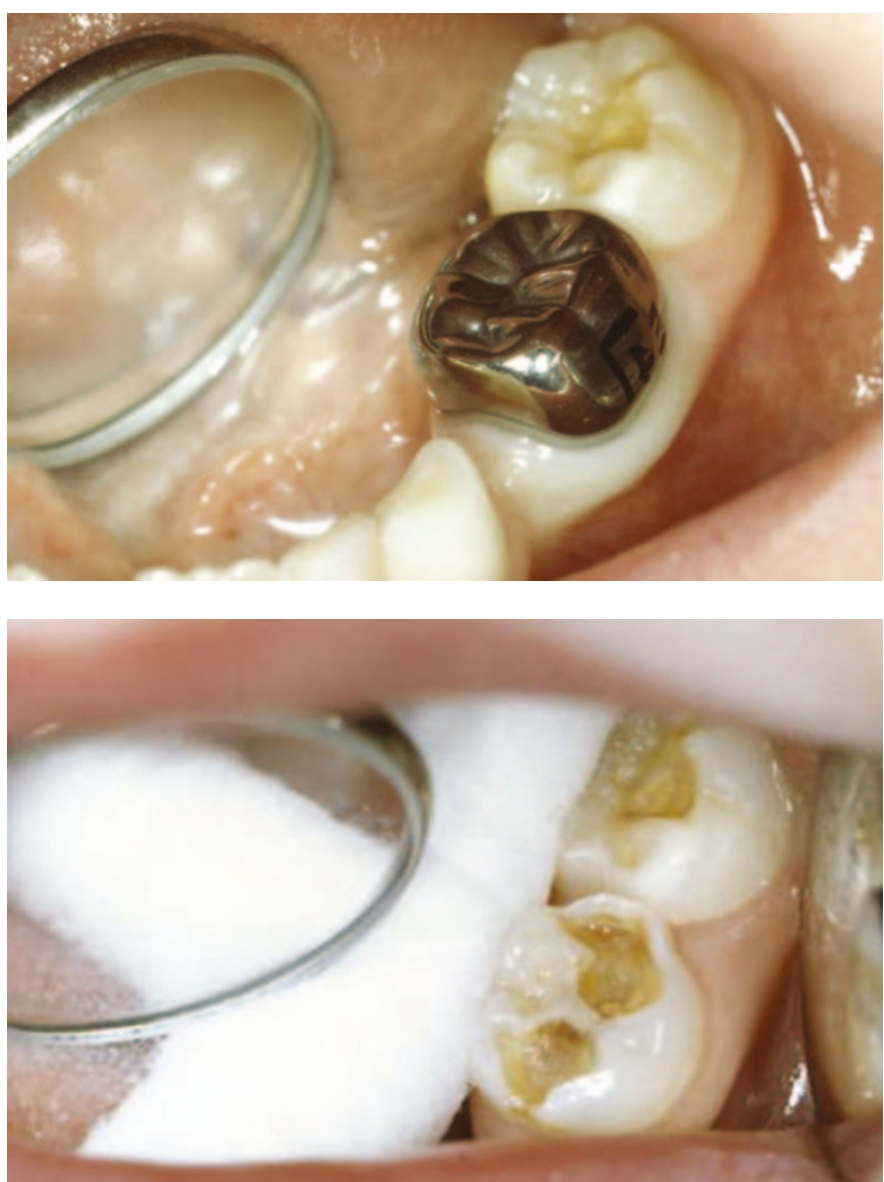

Figs $1 \mathrm{a}$ and $1 \mathrm{~b}$ Management of a carious primary second molar, using the Hall technique

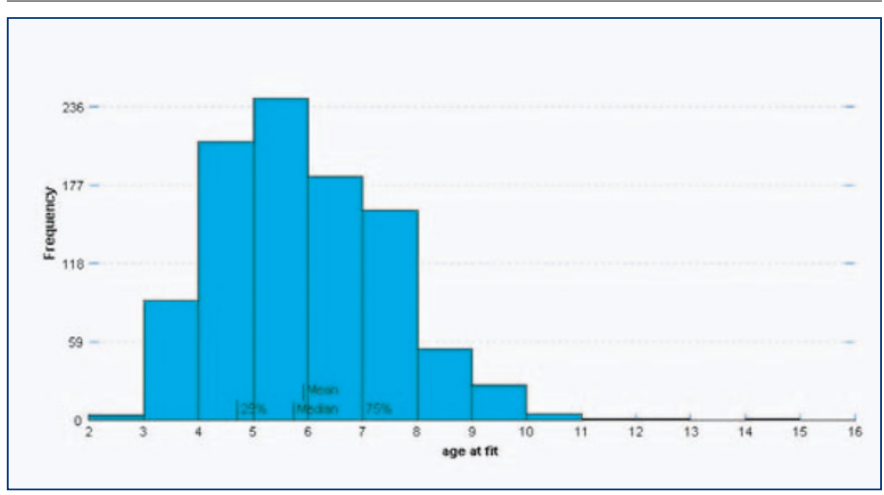

Fig. 2 Distribution of children's ages (in years) at crown fit

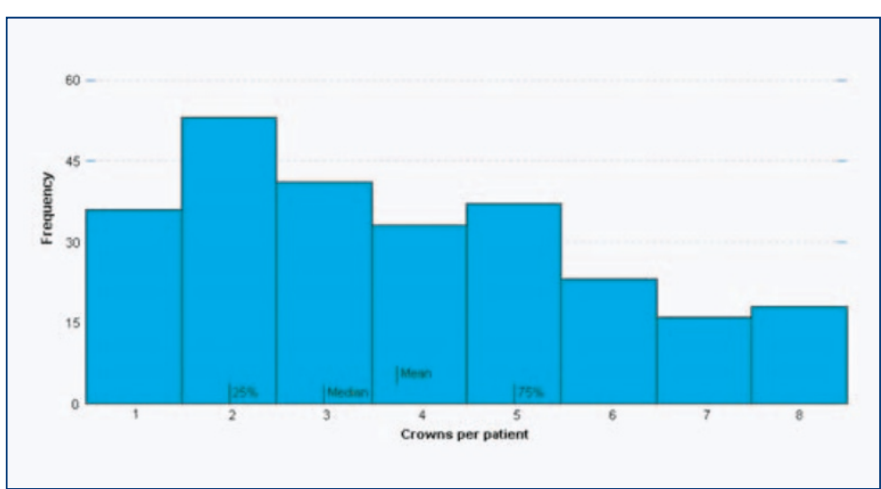

Fig. 3 Distribution of numbers of crowns per patient

the generalisability of the technique, a pilot study of the technique has been carried out by the authors and reported in a web-based journal. $^{30}$ This showed that all patients, and the majority of parents and practitioners found the technique acceptable. However, 


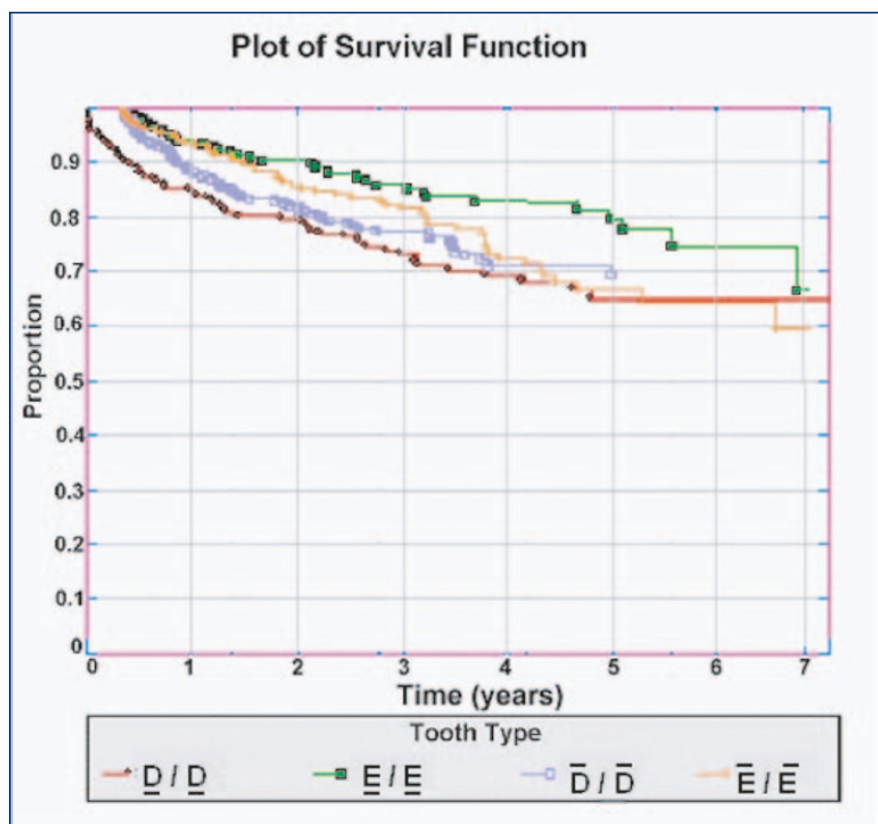

Fig. 4 Plot of survival function for crowns

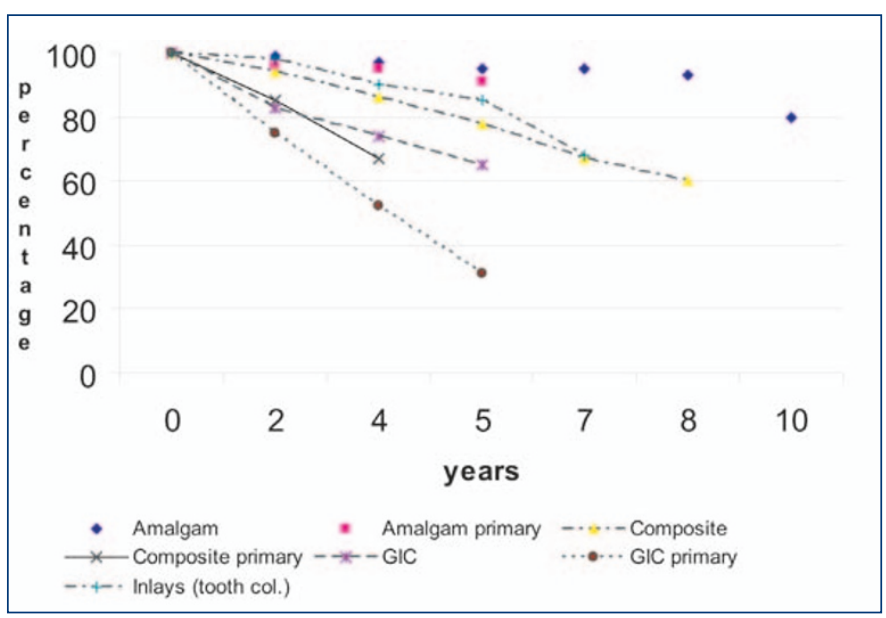

Fig. 5 Estimates of longevity of dental restorations (in permanent and primary teeth) Reprinted with permission from Evidence Based Dentistry (Chadwick et al. 2002; 3: 96-99), Copyright 2002, Macmillan Publishers Ltd.

it must also be clearly demonstrated that the technique is effective in managing dental caries before its use could be generally recommended. A randomised control clinical trial is currently underway to determine the technique's efficacy and cost effectiveness.

The need for further investigation of alternative techniques for managing carious primary molars, such as a prevention-only approach, or the Hall technique, might be questioned in view of the fact that there are conventional techniques available of proven efficacy, recommended for use, and part of the standard teaching at all dental schools. However, the evidence indicates that these techniques, based on early diagnosis of caries assisted by the use of radiography, followed by conventional restoration involving the use of high speed hand pieces and local anaesthetic injections, are just not being applied in primary care. The care index for 5-year-olds remains around the 10\% level, as it has done for years, and too many children have to cope with dental pain and extractions as a regular part of their childhood. Ideally, all children should have access to high quality preventive and restorative care, but until that time comes, the need for exploration of alternative techniques which are simpler, and more acceptable to children, their parents and dental practitioners, remains.

\section{CONCLUSION}

Hall technique restorations placed over primary molars with decay clinically into dentine, by a single operator in general dental practice, have a similar success rate to some other, more conventional, restorative techniques. The technique requires further evaluation through a prospective randomised control clinical trial before its use could be generally recommended.

The authors acknowledge the support of EastRen, The Chief Scientists Office of the Scottish Executive and 3M/ ESPE for this study.

1. Qvist V, Laurberg L, Poulsen A, Teglers P T. Longevity and cariostatic effects of everyday conventional glass-ionomer and amalgam restorations in primary teeth: three-year results. JDentRes 1997; 76: 1387-1396.

2. Welbury R R, Walls A W, Murray J J, McCabe J F. The 5-year results of a clinical trial comparing a glass polyalkenoate (ionomer) cement restoration with an amalgam restoration. BrDent J 1991; 170: 177-181.

3. Attin T, Opatowski A, Meyer $C$ et al. Three-year follow up assessment of Class II restorations in primary molars with a polyacid-modified composite resin and a hybrid composite. Am J Dent2001; 14: 148-152.

4. Duggal M S, Toumba KJ, Sharma N K. Clinical performance of a compomer and amalgam for the interproximal restoration of primary molars: a 24-month evaluation. $\mathrm{Br}$ Dent $J$ 2002; 193: 339-342.

5. Gross L C, Griffen A L, Casamassimo P S. Compomers as Class II restorations in primary molars. Ped Dent 2001; 23: 24-27.

6. Marks L A, Weerheijm K L, van Amerongen W E et al. Dyract versus Tytin Class I restorations in primary molars: 36 months evaluation. Caries Res 1999; 33: 387-392.

7. Roeters J J, Frankenmolen F, Burgersdijk R C W, Peters T C R. Clinical evaluation of Dyract in primary molars: 3-year results. Am J Dent 1998; 11: 143-148.

8. Welbury R R, Shaw A J, Murray J J et al. Clinical evaluation of paired compomer and glass ionomer restorations in primary molars: final results after 42 months. $\mathrm{Br}$ Dent J 2000; 189: 93-97.

9. Donly K J, Segura A, Kanellis M, Erickson R L. Clinical performance and caries inhibition of resin-modified glass ionomer cement and amalgam restorations. JAm DentAssoc 1999; 130: 1459-1466.

10. Papagiannoulis L, Kakaboura A, Pantaleon F, Kavvadia K. Clinical evaluation of a polyacidmodified resin composite (compomer) in Class II restorations of primary teeth: a twoyear follow-up study. Ped Dent 1999; 21:231-234.

11. Tickle M K, Milsom K M, Kearney-Mitchell P et al. The fate of the carious primary teeth of children who regularly attend the general dental service.[comment]. Br Dent J 2002: 192: 219-223.

12. Levine R S, Pitts N B, Nugent $Z$ J. The fate of 1,587 unrestored carious deciduous teeth: a retrospective general dental practice based study from northern England. [comment]. $\mathrm{Br}$ Dent J 2002; 193: 99-103.

13. Fayle S A, Welbury R R, Roberts J F. British Society of Paediatric Dentistry: a policy document on management of caries in the primary dentition. Int J Paed Dent 2001; 11: 153-157.

14. Page J, Welbury R R. Operative treatment of dental caries. In Welbury R R (Ed). Paediatric Dentistry. $2^{\text {nd }}$ ed. pp 146-147. Oxford: Oxford University Press, 2001.

15. Randall $R$, Vrijhoef $M$, Wilson N. Efficacy of preformed metal crowns vs amalgam restorations in primary molars: a systematic review. JADA 2000; 131:337-343.

16. Scottish Dental Practice Board Annual Report 2001/2002 Trinity Park House, Edinburgh.

17. Scotland's National Dental Inspection Programme 2003. http://www.dundee.ac.uk/ ndip/index.htm.

18. O'Brien M. Children's dental health in the United Kingdom. London: HMSO 1994.

19. Milsom K M, Tickle M, Blinkhorn A S. Dental pain and dental treatment of young children attending the general dental service. BrDent J 2002; 192: 280-284.

20. Pitts N B, Nugent $Z$ J, Smith P A. Scottish Health Boards Dental Epidemiological Programme. Report on 1997/1998 Survey of 5-year-old children http://www.dundee.ac.uk/dhsru/shbdep97.

21. Kaplan E L, Meier P. Nonparametric estimation from incomplete observations J Amer Stat Assoc 1958; 53: 457-481.

22. Mantel $N$, Haenszel W. Statistical aspects of the analysis of data from retrospective studies of disease. J Nat Cancer Institute 1959; 21 : 719-748.

23. Chadwick B, Dummer P, Dummer F et al. How long do fillings last? (reviewed by: Asbjorn Jokstad) Evidence Based Dent 2002; 3: 96-99.

24. McDonald S P, Sheiham A. A clinical comparison of non-traumatic methods of treating dental caries. Int Dent J 1994; 44: 465-470.

25. Faroog N S, Coll J A, Kuwabara A, Shelton P. Success rates of formocresol pulpotomy and indirect pulp therapy in the treatment of deep dentinal caries in primary teeth. Pediatr Dent 2000; 22: 278-86.

26. Ribeiro C C, Baratieri L N, Perdigao J et al. A clinical, radiographic, and scanning electron microscopic evaluation of adhesive restorations on carious dentin in primary teeth. Quint Int 1999; 30: 591-599.

27. Foley J, Evans D J P, Blackwell A. Partial caries removal and cariostatic materials in carious primary molar teeth: a randomised controlled clinical trial. Br Dent J 2004; 197: 697-701.

28. Duggal M S, Nooh A, High A. Response of the primary pulp to inflammation: a review of the Leeds studies and challenges for the future. Eur J Paediatr Dent 2002; 3: 111-114.

29. Kidd $E A M$, Pitts N B. A reappraisal of the value of the bitewing radiograph in the diagnosis of posterior approximal caries. Br Dent J 1990; 169: 195-200.

30. Evans D J P, Southwick CA P, Foley J I etal. The Hall technique: a pilot trial of a novel use of preformed metal crowns for managing carious primary teeth. 2000 http://www.scottishdental.org/pbrn/research/papers/rt03.htm 